\title{
O SIG DO PASSADO TEM FUTURO? A EXPERIÊNCIA DO HÍMACO COMO SUBSÍDIO AO DEBATE
}

Luis Ferla

\section{Resumo}

A análise do uso de tecnologias pelo historiador tem que dar conta de ambiguidades incontornáveis. De saída, a informática demanda precisóes que a história não pode fornecer. Por outro lado, as tecnologias prometem ganhos metodológicos sedutores. Assim, o equilíbrio entre desafios e oportunidades condiciona o trabalho daqueles historiadores que buscam explorar as tecnologias digitais. Como no Brasil estes ainda são poucos, faz sentido compartilhar experiências e reflexóes sobre o tema. Esse é o objetivo do presente artigo, que oferece à análise o percurso de um grupo de pesquisas da Unifesp, o Hímaco (História, mapas e computadores). $\mathrm{O}$ uso de geotecnologias, particularmente dos Sistemas de Informaçôes Geográficas (SIGs), caracteriza os projetos do grupo.

Palavras-chave: SIG histórico; humanidades digitais; história digital. 
 \\ Does the GIS of the past have a future? Hímaco's experience as a subsidy to the debate
}

\begin{abstract}
:
The analysis of the use of technologies by historians has to consider many ambiguities. From the outset, computing demands precisions that history can not provide. On the other hand, technologies promise seductive methodological gains. Thus, the balance between challenges and opportunities shapes the work of those historians who seek to exploit digital technologies. As in Brazil these are still few, it makes sense to share experiences and reflections on the theme. This is the meaning of this article, which offers the analysis of the course of a research group of Unifesp, the Himaco (History, maps and computers). The use of geotechnologies, particularly Geographic Information Systems (GIS), characterizes the projects of the group.
\end{abstract}

Keywords: historical GIS; digital humanities; digital history.

\section{INTRODUÇÃO}

A tecnologia dos sistemas de informações geográficas (SIG) diz respeito aos historiadores, quanto mais não fosse porque a dimensão espacial pode e deve ser priorizada em muitos estudos de nossa área. Mas a sua incorporação em nosso cotidiano profissional é algo bastante complexo. Muito já se escreveu acerca do delicado balanço entre as enormes oportunidades e os perturbadores desafios implicados no uso de SIGs em investigaçóes históricas.1 De todo modo, a hora das tecnologias em humanidades, em geral, e do SIG em estudos históricos, em particular, parece ter mesmo chegado, se consideramos o decaimento radical do custo das infraestruturas implicadas e a superação geracional de muitas resistências ao uso da computação entre os humanistas. Mas, por outro lado,

\footnotetext{
${ }^{1}$ Ver, por exemplo, Gregory e Ell, 2007; e Knowles, 2008.
} 
existem incompatibilidades perturbadoras entre o mundo dos computadores e o mundo das humanidades. Enquanto o primeiro não admite a ambiguidade e a imprecisão, este não pode existir sem elas, mormente em estudos históricos, com objetos temporalmente fugidios por definição (Bodenhamer, 2008, p. 222). Ainda que a resposta a esse problema náo seja simples, o acúmulo de experiência da comunidade envolvida com o SIG histórico já possibilita algum amadurecimento de metodologias e estratégias próprias para lidar com essa contradição, aprimorando, por exemplo, o uso de metadados e as simbologias de imprecisão.

Com essa perspectiva relativamente otimista, eu e o Professor Janes Jorge, meu colega no Departamento de História da Unifesp, criamos o grupo Hímaco - História, Mapas e Computadores, em agosto de 2010. O seu objetivo era justamente discutir as possibilidades e os desafios implicados na utilização de tecnologias digitais no trabalho do historiador, com especial ênfase para os SIGs. Àquela época, tratava-se de um grupo de estudos e debates, prescindindo por então de máquinas e laboratórios. Semanal ou quinzenalmente, em alguma sala de aula disponível no horário entre as aulas do vespertino e noturno, discutíamos com uma população algo flutuante de alunos de graduação do curso de História alguns dos textos referenciais de SIG histórico e assuntos correlatos. 2

Ainda que esse período inicial tenha sido fundamental para o acúmulo teórico referente ao tema e para aglutinar um primeiro grupo de alunos que iria perseverar conosco por mais tempo, crescia a necessidade de aplicar aqueles conhecimentos teóricos em investigaçóes práticas, ou seja, ansiávamos em "pôr a mão na massa". Mas como? Não tínhamos nem o espaço, nem os equipamentos, nem os necessários. E mesmo que adquiríssemos tudo isso de pronto, havia que admitir que nosso conhecimento na área ainda era incipiente para a proposição confiante de sólidos projetos de pesquisa, capazes

${ }^{2}$ Dentre os quais, aqueles arrolados na bibliografia do presente artigo.

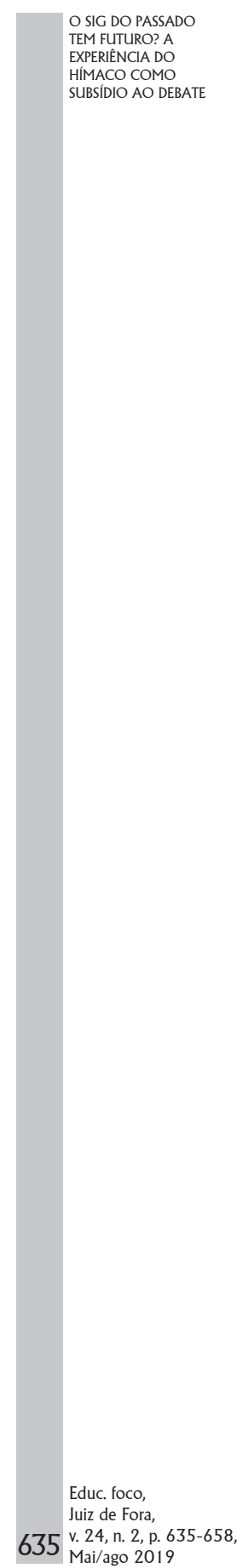




\begin{abstract}
tus FERıA de sensibilizar as agências de fomento. A solução encontrada foi uma parceria com outra instituição e o desenho de um projeto-piloto de pesquisa.
\end{abstract}

\title{
2. OS PROJETOS DO GRUPO HÍMACO
}

\subsection{A parceria com o Arquivo Público do Estado de Sáo Paulo e o PRojeto-Piloto}

Em março de 2011, a partir de contatos com o então diretor do Departamento de Preservação e Difusão do Acervo, Lauro Ávila Pereira, foi estabelecida a parceria com o Arquivo Público do Estado de São Paulo, através de seu Núcleo de Acervo Cartográfico.3 O ganho imediato com a cooperação que ali se iniciava foi o aumento da qualidade das reflexóes do grupo, que passava a incorporar profissionais e estudantes de geografia, o que nos aproximava da interdisciplinariedade que caracteriza as melhores pesquisas de SIG histórico, além do acesso facilitado ao acervo cartográfico daquela instituição.

A nova conjuntura propiciou ao grupo a confiança para construir um projeto de pesquisa. $\mathrm{O}$ seu objetivo deveria ser o de experimentar na prática os tais desafios do uso de SIG em história, além de buscar as capacitaçôes metodológicas e tecnológicas necessárias. Por isso, fazia sentido que tal projeto tivesse um caráter piloto, experimental. Nesse sentido, o percurso de nosso grupo é algo heterodoxo. Normalmente, e esse provavelmente deve ser o caso do que relatam os meus colegas nesse volume, a tecnologia se apresenta como uma alternativa otimizadora da busca de resultados de investigaçóes já postas, ainda que potencialmente possa provocar ressignificaçóes e novas abordagens. Nós, por outro lado, estudamos as características da tecnologia e seus possíveis impactos metodológicos e mesmo epistemológicos antes mesmo de termos à mão um problema historiográfico

\footnotetext{
${ }^{3}$ Parceria oficializada por meio de assinatura de Termo de Convênio em setembro de 2012, e renovada em abril de 2015 e novamente em abril de 2018.
} 
concreto. Inevitavelmente, como de fato se deu, essa lacuna acabaria por limitar o alcance de nossas reflexóes e das possibilidades de construir conhecimento.

Colocada a demanda, portanto, da definição de um projeto-piloto de pesquisa, esse teve por título "As enchentes na cidade de Sáo Paulo: abrangência espacial e impactos sociais (1870-1940)". Esse recorte atendeu a alguns critérios previamente estabelecidos. $\mathrm{O}$ primeiro deles é que a pesquisa deveria partir do conhecimento historiográfico acumulado por participantes do grupo, dado que a tecnologia não substitui conhecimento, apenas possibilita, quando muito, uma melhor articulação dele. Nesse momento, além de meu colega Janes Jorge, especialista em história ambiental e autor do livro "Tietê, o rio que a cidade perdeu" (Jorge, 2006) e de vários artigos referentes à história das águas em São Paulo, o grupo contava também com o Professor Fábio Alexandre dos Santos, da Unifesp de Osasco, da mesma forma estudioso do tema, havendo publicado o livro "Domando águas: salubridade e ocupação do espaço na cidade de São Paulo" (Santos, 2011). O segundo critério tinha relação com a densidade historiográfica do recorte escolhido. Como um dos objetivos do grupo é a difusão da tecnologia do SIG junto à comunidade de historiadores, era importante que nossa pesquisa encontrasse audiência nesse meio, e a história da cidade de Sáo Paulo naquele período sem dúvida tinha esse perfil. Por fim, o que é obvio, a pesquisa proposta deveria ter na dimensão espacial um componente fundamental.

De posse de um projeto de pesquisa consistente, conseguimos financiamentos junto ao $\mathrm{CNPq}$ e à Fapesp que viabilizaram sua execução. Mas registre-se aqui que o projeto aprovado deixava claro que o estudo piloto era um meio para se alcançar outro fim: a capacitaçáo de um grupo de pesquisadores no uso do SIG histórico. Tanto é assim que o projeto que as agências aprovaram tinha como título: "Implementação da tecnologia de Sistemas de Informações Geográficos (SIG) em investigaçôes históricas", onde o

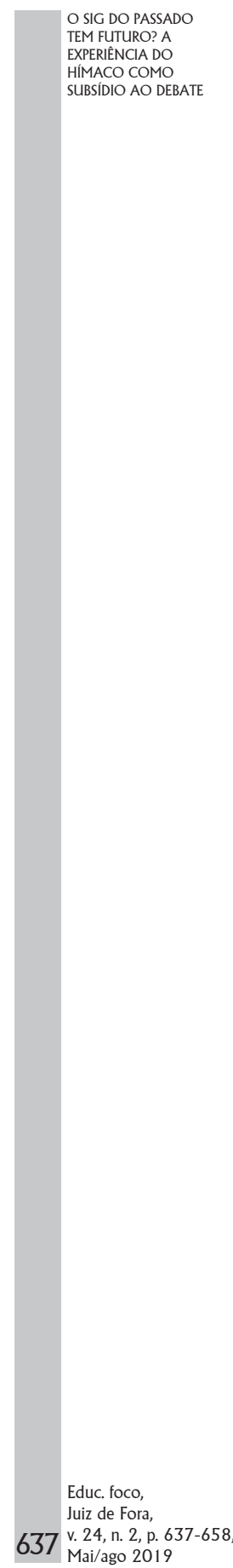


mapeamento das enchentes ocupava o centro da metodologia de pesquisa. Os financiamentos, por sua vez, permitiram a aquisição de equipamentos e a concessão de bolsas de pesquisa. Dessa forma, foi possível estruturar um laboratório, nas dependências do Arquivo do Estado.4 O projeto foi ali desenvolvido, de julho de 2013 a junho de 2015.

O grupo estudou e mapeou duas enchentes na cidade de Sáo Paulo do período abordado, a de 1887 e a de 1929. A primeira tem sua importância por ser considerada um marco no "encontro da cidade com as águas", representando um momento em que a rápida urbanizaçáo da cidade alcançava as várzeas de seus principais rios (Kogan, 2013); e a segunda é interessante náo apenas pelas dimensôes que alcançou, mas principalmente por estar associada a manipulaçóes no sistema hídrico da cidade promovidas pela empresa Light, Tramway $\&$ Power Ltd., de forma a atender alguns de seus interesses de controle fundiário da regiáo da bacia do Rio Pinheiros (conforme facultava a lei Lei $n^{\circ} 2.249$, de 1927; ver Seabra, 1987; Pontes, 1995; Jorge, 2006; Santos, 2011). Apesar de sua importância historiográfica, a enchente de 1929 nunca havia recebido uma representação cartográfica, o que confere importância adicional ao mapa produzido pelo grupo Hímaco (figura 1).

\footnotetext{
${ }^{4}$ Em junho de 2016, os equipamentos, financiados pelo CNPq e pela Fapesp, foram transferidos para o campus Guarulhos da Unifesp, para estruturar o Laboratório de Humanidades Digitais da universidade, do qual o Hímaco faz parte. Desde entáo, o laboratório do Apesp está equipado com computadores da própria instituição, o que evitou qualquer solução de continuidade de seu uso pelo grupo. Como discutido mais adiante, neste são priorizadas as interlocuçốes com pesquisadores que possuem interface com nossos projetos e também as reuniôes ordinárias do grupo, ao passo que aquele é o espaço preferencial para a interação com o alunado da Universidade.
} 


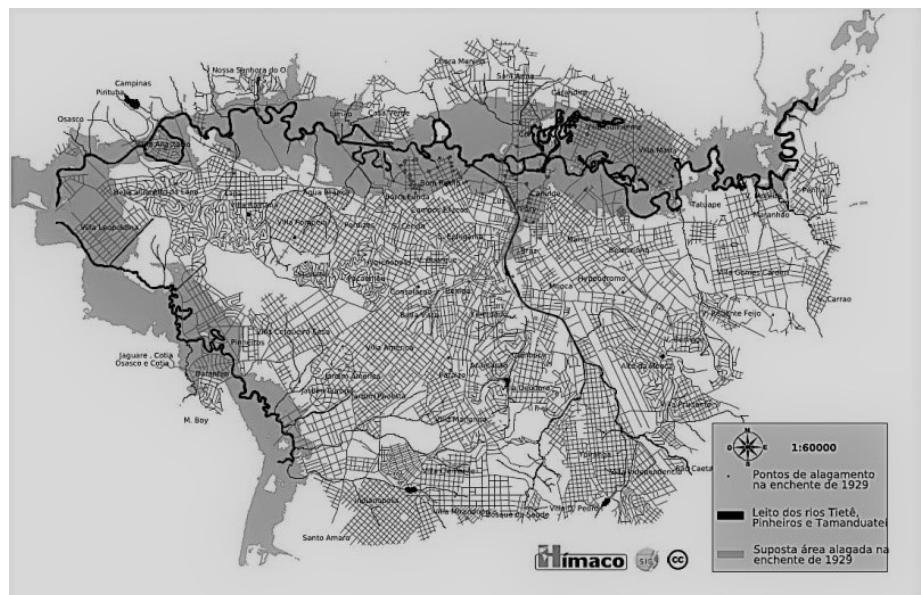

Figura 1 - Visualização da enchente de 1929 em São Paulo (fonte: www.unifesp. br/himaco)

Todos os resultados do projeto, assim como a documentaçáo histórica que lhes deu suporte, se encontram disponíveis no site do grupo (www.unifesp.br/himaco). Além disso, todo o material produzido pelo projeto possui o correspondente arquivo de metadados, igualmente disponível para, que detalha as metodologias empregadas e as aproximaçóes e hipóteses assumidas no processo de sua elaboração. Esse é um procedimento de boa prática científica, em geral, mas que ganha uma importância adicional ao se tratar de uso de tecnologias em pesquisas históricas, pois a computação tende a conferir uma autoridade abusiva aos resultados alcançados. Essa é uma das principais estratégias para tratar as incompatibilidades entre os mundos da tecnologia e da história referidas acima.

No mesmo período em que foi desenvolvido o projetopiloto, alguns membros do grupo participaram também do Projeto PIPAG - Projeto de Inventário e Pesquisa Arqueológica de Guarulhos, coordenado pela minha colega Cláudia Plens. A nossa atribuição ali foi justamente fazer o mapeamento do patrimônio inventariado. Os resultados se encontram sintetizados e discutidos no dossiê do projeto publicado na Revista do Museu de Arqueologia e Etnologia da USP (Ferla 
et al, 2016, disponível em http://www.revistas.usp.br/revmae/ article/view/119013, acessado em 20 de março de 2018).

\subsection{O projeto Pauliceia 2.0}

A experiência do projeto-piloto conferiu ao grupo um novo patamar de atrevimento para novas proposiçóes na seara do uso de geotecnologias em estudos do passado. Ao longo do ano de 2015, o Hímaco discutiu, interna e externamente, as possibilidades para seu novo projeto. Havia a disposição em aprofundar as experiências de interdisciplinariedade, trabalho colaborativo e de ciência aberta5, ao mesmo tempo em que se buscava fazer uso das capacitaçôes historiográfica e tecnológica adquiridas pelo grupo em sua trajetória até ali. Consolidavase uma proposta de mapeamento colaborativo da história da cidade de São Paulo, ainda com o recorte temporal de fins do século XIX e inícios do XX (1870-1940).

No entanto, também ficava claro que os desafios de um projeto com essas características demandaria a busca de novas parcerias. $\mathrm{O}$ edital eScience da Fapesp, publicado em novembro de 2015, iria fornecer as possibilidades de financiamento e o arcabouço multi-institucional para o projeto sair do papel. Esse programa tem o objetivo de "encorajar abordagens novas, ousadas e náo convencionais para pesquisa de ponta, multidisciplinar, integrando grupos de pesquisa em Computação e em outras áreas. Esta colaboração visa investigar como avanços de pesquisa em Computação podem ajudar a vencer desafios científicos e tecnológicos em outros domínios, e vice-versa".6 A partir da publicação do edital, o grupo passou a buscar interlocuçóes que viabilizassem a apresentação de uma proposta. Uma equipe de pesquisa multidisciplinar, envolvendo profissionais de quatro instituiçóes diferentes, acabou sendo constituída. Aos integrantes do Hímaco,

\footnotetext{
${ }^{5}$ Para introdução ao tema da ciência aberta, ver Albagli, 2015.

${ }^{6}$ http://www.fapesp.br/publicacoes/2015/folder_escience.pdf, acessado em 20 de março de 2018.
} 
majoritariamente oriundos do campus Guarulhos da Unifesp e do Arquivo Público do Estado, juntaram-se pesquisadores do Instituto de Ciência e Tecnologia da Unifesp (campus São José dos Campos), do Instituto Nacional de Pesquisas Espaciais, e da Emory University, dos Estados Unidos.

A partir do esboço apresentado pelo grupo Hímaco, a equipe assim constituída debateu e aprimorou a proposta a ser submetido à Fapesp, e o resultado foi o Projeto "Pauliceia 2.0: mapeamento colaborativo da história de São Paulo (1870-1940)", aprovado em setembro de 2016 e com vigência de fevereiro de 2017 a janeiro de 2019. A proposta apresentada à Fapesp teve o autor e Karine Reis Ferreira, da Divisão de Processamento de Imagens do INPE, como pesquisadores principais. O projeto previa o desenvolvimento e a disponibilização na rede mundial de computadores de uma base cartográfica digital histórica da cidade de São Paulo, referente ao período de sua modernização urbanoindustrial (1870-1940), associada a uma interface que permita a interatividade de pesquisadores interessados, de forma a que estes possam alimentar a base disponibilizada com eventos espacializáveis de suas próprias investigaçóes. Dessa forma, pesquisadores interessados poderão produzir mapas e visualizaçóes de suas respectivas pesquisas, a partir da base fornecida, ao mesmo tempo em que acabarão por enriquecer a base disponibilizada com as informaçóes que terão alimentado ao sistema.7 Pretende-se, assim, criar as condiçóes para o enriquecimento das abordagens da história de São Paulo daquele período, fazendo-o em conformidade com os mais recentes e interessantes desdobramentos das humanidades digitais, voltados ao trabalho colaborativo e à livre circulação do conhecimento.

\footnotetext{
${ }^{7}$ Uma versão preliminar da plataforma está disponibilizada para testes desde outubro de 2018 (www.pauliceia.dpi.inpe.br), e a versão definitiva ficará pronta em janeiro de 2021.
}

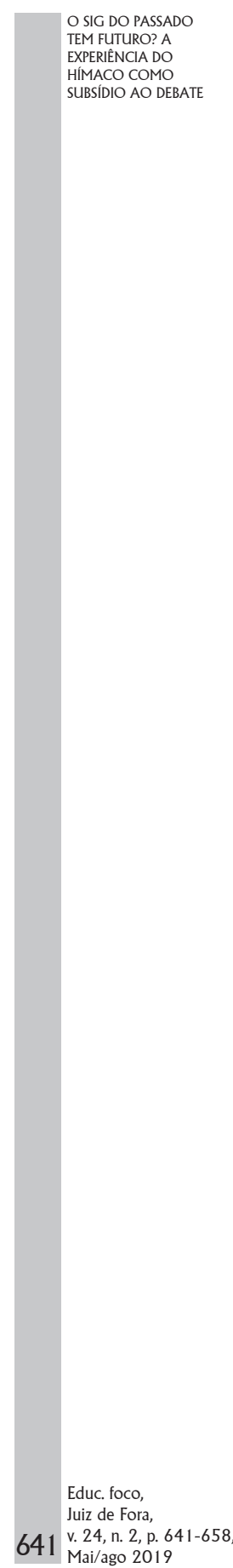



E DA LIVRE CIRCULAÇÃO DO CONHECIMENTO

Desde a sua constituição, em 2010, o grupo Hímaco procurou construir uma identidade calcada no trabalho coletivo e nos princípios da ciência aberta e do livre compartilhamento dos resultados alcançados. Nesse sentido, há coincidência com o ethos predominante nas comunidades que reivindicam as humanidades digitais. Nesse ecossistema, tais valores são sistematicamente reiterados (Spiro, 2012).

Os mais recentes desdobramentos dos regimes de produção do conhecimento permitem que este possa ser desenvolvido de forma cada vez mais colaborativa e que seja cada mais facilmente compartilhado. Que assim seja certamente pode ser entendido por algumas características das tecnologias envolvidas, relacionadas ao estabelecimento de redes horizontais e à facilitação do tráfego e do intercâmbio eletrônico de informaçóes. Além disso, o próprio surgimento histórico da computaçáo moderna está relacionado à cultura universitária e científica, por sua vez justificada socialmente pela ideia do conhecimento como bem público (Carlotto e Ortellado, 2011). Na década de cinquenta, quando surgem os primeiros computadores comerciais de grande porte, era muito restrito o universo de profissionais dedicados a dotar essas máquinas da devida programação, e o ambiente que iria possibilitar isso não poderia ser outro que não fosse $o$ da cooperação aberta e incondicional (Carlotto e Ortellado, 2011, p. 78). Já o aparecimento dos primeiros computadores pessoais, em fins da década de setenta, deve muito aos movimentos contraculturais da época, principalmente no que tinham de afirmaçáo do indivíduo, marcadamente do jovem, frente aos diversos constrangimentos sociais por eles percebidos. O computador pessoal representava uma vitória do indivíduo frente ao Estado e às corporaçóes, até então os únicos proprietários e controladores exclusivos da tecnologia da informação. 
É verdade, porém, que desde então outras tendências, em sentido oposto, se desenvolveram. A partir da famosa carta de Bill Gates a um clube de hackers do Vale do Silício8, questionando o livre uso e reprodução de programas de computador, há uma ofensiva generalizada e extremamente bem-sucedida voltada à mercantilizaçáo da tecnologia da informação e do conhecimento produzida por ela. Também a cultura científica e universitária assistiu a uma rápida degradação da ideia de conhecimento público e aberto, em prol das concepçôes de competitividade e propriedade intelectual (Carlotto e Ortellado, 2011, p. 93).

Apesar disso e como afirmado acima, as humanidades digitais parecem constituir um ecossistema ainda bastante saudável para as práticas de compartilhamento de conhecimento e do trabalho colaborativo, no que se articulam com facilidade com o que subsiste disso no ambiente acadêmico e científico. O papel da rede mundial de computadores, nesse aspecto, principalmente a partir da afirmação da chamada web 2.0, caracterizada náo apenas pela ampla disponibilizaçáo de estudos e investigaçóes, como pela oportunidade amplamente favorecida de sua produção colaborativa, permite cada vez com maior facilidade a realização prática daqueles valores teóricos. Dessa forma, o historiador que for trabalhar com as humanidades digitais tem hoje à disposiçáo uma gama de possibilidades tecnológicas para a ampla divulgação dos resultados de suas pesquisas, o que vale também para a própria produção colaborativa delas.

Procurando dar consequência a essas diretrizes e possibilidades, o grupo Hímaco prioriza a utilização de livres em seus projetos, com destaque para o programa de sistema de informaçáo geográfica gvSIG, alternativa livre e de código aberto surgida em 2004 na Espanha e que conta hoje com uma comunidade de usuários bastante difundida internacionalmente. O grupo utiliza o gvSIG desde 2011, e

\footnotetext{
${ }^{8}$ A carta foi escrita em 1976 e pode ser acessada em: http://cryptnet.net/mirrors/ texts/gates1976.html (acessado em 29 de março de 2018).
}

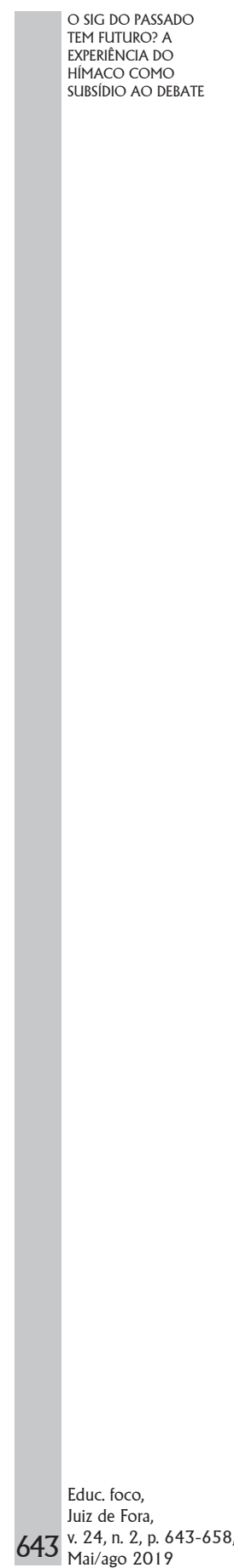

Mai/ago 2019 
a experiência tem sido, até o momento, bastante satisfatória. Registre-se que uma pretensa desvantagem referente à falta de uma estrutura de suporte que o software proprietário fornece não existe de fato, pois a comunidade de usuários mantém listas de discussóes bastante ativas e eficientes para a resolução de problemas. Por outro lado, há bastante identidade entre o grupo Hímaco e o projeto gvSIG, na ênfase da defesa dos valores referidos acima.9

Além disso, há outras vantagens adicionais do uso de livre referentes ao contexto do grupo e de seus projetos. $\mathrm{O}$ SIG histórico é praticamente desconhecido da comunidade de historiadores com a qual interage o grupo, e a estratégia de sua difusão ali depende de uma ampla facilidade de acesso às tecnologias implicadas. Dessa forma, os primeiros contatos com o devem ser permitidos e estimulados a quaisquer interessados, em casa, na universidade ou no trabalho, que podem perseverar ou não na sua utilização em suas pesquisas. A alternativa proprietária, de saída, representaria a restrição do acesso a um grupo pequeno e previamente definido, limitando severamente, assim, o alcance desejado e as possibilidades de engajamento. Por fim, a questão do custo baixo ou inexistente, que não é definidora da tecnologia livre, mas é uma característica sua quase sempre presente, é fundamental para a viabilidade de muitos projetos, mormente aqueles que envolvem instituiçóes públicas, como aqueles desenvolvidos pelo grupo.

O percurso do grupo desde sua fundação procurou ser sistematicamente coerente com tais perspectivas, mas é no projeto Pauliceia 2.0 que elas encontram a sua mais completa expressão prática. Em primeiro lugar, porque o seu objetivo precípuo, a disponibilização de uma plataforma para uso aberto e sem restriçóes de quaisquer interessados, e

\footnotetext{
${ }^{9}$ Ao ponto de o Hímaco ser reconhecido como "sócio honorário" da Asssociação gvSIG (http://www.gvsig.com/pt/associacao-gvsig/membros-de-honra, acessado em 24 de março de 2018),
} 
o compartilhamento irrestrito de todo material ali alimentado por eles, é quase que por definição a prática da ciência aberta e da circulação livre do conhecimento. Em segundo lugar, não serão apenas os dados históricos espacializados que serão assim compartilhados, mas também toda a tecnologia e a metodologia desenvolvidas pelo projeto.10 Por fim a comunidade atinente à proposta, os pesquisadores da história da cidade de São Paulo, vem sendo instada a participar do desenvolvimento mesmo do projeto, de diversas maneiras diferentes, colaborando no aprimoramento do resultado final a ser alcançado. Por exemplo, no dia 4 de abril de 2017, no auditório do Arquivo Público do Estado de São Paulo, a equipe do projeto organizou um evento de apresentação do Pauliceia 2.0 aos possíveis interessados. Como resultado de um intenso esforço de divulgação 11, o evento contou com mais de 120 pessoas presentes, e as transmissóes ao vivo, via redes sociais, tiveram conjuntamente mais de mil visualizaçôes. 12 Um ano e meio depois, um outro evento lançou a versão beta da plataforma, em 30 de outubro de 2018, no mesmo auditório, com mais de setenta pessoas presentes e também com mais de mil visualizaçóes da transmissão em video pelas redes sociais.13 Tais iniciativas tiveram dois principais objetivos: divulgar propriamente o projeto e receber sugestóes

\footnotetext{
${ }^{10}$ Aqui é importante registrar a firme posição dos colegas do INPE, instituição que congrega a mair parte dos cientistas da computação da equipe do projeto, na defesa do livre compartilhamento da tecnologia a ser desenvolvida, e isso desde os primeiros contatos com eles para discutir a parceria.

${ }^{11}$ Dentre outros canais de divulgação, o evento foi veiculado pela Agência Fapesp. Ver em: http://agencia.fapesp.br/pauliceia_20_mapeamento_colaborativo_da_ historia_de_sao_paulo_18701940/25017/; acessado em 23 de janeiro de 2018.

${ }^{12} \mathrm{~A}$ apresentação do projeto (primeira parte do evento), pode ser acessada em https:// www.facebook.com/arquivoestado/videos/1361653267206845/ . Ver também galeria de fotos em: http://www.arquivoestado.sp.gov.br/site/multimidia/fotos/ ver/projeto-pauliceia-20. Sites acessados em 23 de janeiro de 2018.

${ }^{13} \mathrm{Ver}$ a apresentação na íntegra em https://www.facebook.com/events/arquivop\%C3\%Bablico-do-estado-de-s\%C3\%A3o-paulo/lan\%C3\%A7amentopauliceia-20-vers\%C3\%A3o-beta/2650315988315498/, acessado em 10 de junho de 2019.
}

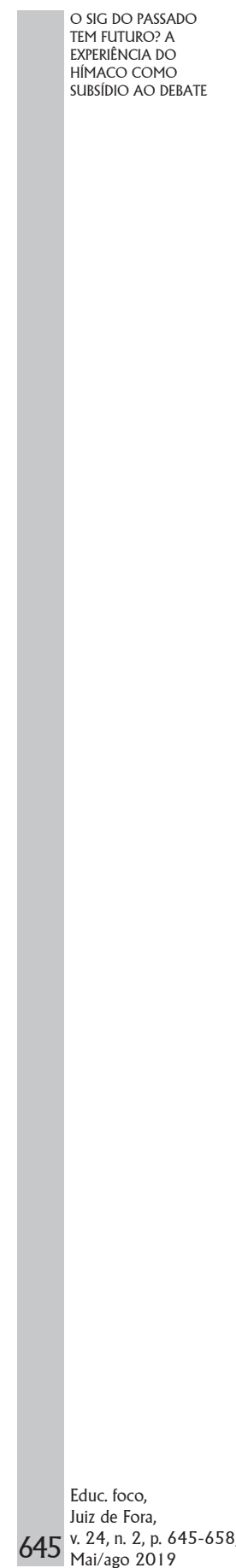


quanto ao seu desenvolvimento. A identidade colaborativa da plataforma a ser desenvolvida implica na sua ampla divulgaçáo junto aos possíveis interessados, de forma a não se incorrer em uma das principais fragilidades de projetos similares que fracassam, qual seja, o pequeno número de acessos e a pouca utilização da ferramenta. Muitas vezes, esse resultado indesejado é consequência de problemas da própria estrutura da ferramenta disponibilizada, mas outras vezes é resultado do desconhecimento da sua existência por parte dos usuários potenciais. Além disso, quando estes são instados a opinar e tecer críticas quanto a características da ferramenta a ser desenvolvida, crescem as possibilidades de participação e engajamento.

No entanto, não bastam a estruturação de laboratórios, o desenvolvimento de projetos consistentes e promissores, e a prática cotidiana da ciência aberta para constituir um ecossistema consistente de utilização das geotecnologias em estudos históricos. No máximo, o que se garante dessa forma é a afirmação de um nicho simpático e produtivo, mas isolado de seus pares por um abismo de estranhamento mútuo. De forma mais óbvia, a livre circulação do conhecimento implica, antes que tudo, que o conhecimento circule, constituindo o que o pensador Bruno Latour chamou de imprescindibilidade do fato científico por parte de agentes de uma rede de interesses comuns (Latour, 2000). Portanto, assumiu-se a perspectiva de que o grupo Hímaco se localiza no contexto de uma comunidade de historiadores e estudantes de história, e tanto seus projetos mais estratégicos quanto seu funcionamento deveriam responder a isso.

\section{AS ESTRATÉGIAS DE INSERÇÃO NO MEIO ACADÊMICO}

\subsection{A CURVA ÍNGREME DE APRENDIZADO E A ALTA ROTATIVIDADE}

Qualquer projeto que envolva SIG e história deve levar em conta que essa é uma tecnologia que possui uma curva 
relativamente íngreme de aprendizado, mormente para pessoas oriundas das humanidades. Além de poder representar uma dificuldade no recrutamento de estudantes e pesquisadores para compor as equipes dos projetos, esse problema pode ainda ser a causa de uma alta rotatividade na sua composição, o que por sua vez demanda recorrentemente energias do grupo voltadas ao treinamento de novos integrantes. A experiência acumulada pelo grupo Hímaco até o momento foi útil não apenas para a identificação desse problema, como para o desenvolvimento de estratégias para responder a ele. Com relação à rotatividade, ficou claro que a concessão de bolsas aos alunos é bastante eficiente para diminuí-la significativamente. Por conta disso, a relação do estudante com a pesquisa se torna, evidentemente, mais compromissada. Com relação ao treinamento na tecnologia, o grupo desenvolveu um tutorial de aprendizado do utilizado (o gvSIG) e disponibilizou-o em sua página na internet.14 É importante ressaltar que esse tutorial pode ser executado integralmente no computador pessoal do usuário, pois não apenas o software utilizado é livre e, consequentemente, pode ser baixado sem restrição alguma, como todos os arquivos necessários para os exercícios estão também disponíveis no site do Hímaco. Além disso, o tutorial é aplicado a estudos históricos, fazendo uso de mapas antigos de São Paulo, o que é um diferencial muito importante em relação a outros materiais de treinamento no também disponíveis na internet. Desse modo, o grupo pode se concentrar melhor em outras atividades dos projetos em que se envolve, ao mesmo tempo em que facilita o aprendizado de pessoas interessadas em participar do grupo ou mesmo em usar SIG em suas próprias pesquisas.

\subsection{A CURRICUlarizaçấo do SIG histórico}

As mudanças dos paradigmas científicos têm como marco fundamental a curricularização das novidades, como já

\footnotetext{
${ }^{14}$ www.unifesp.br/himaco. Também disponível no site do gvSIG: http://www. gvsig.com/pt/difusao/material-didatico (sites acessados em 24/03/2018).
} 
indicava Thomas Kuhn em 1962, na sua obra clássica "Estrutura das Revoluçôes Científicas” (Kuhn, 1997). Ou seja, as novas ideias, teorias, problemas e métodos de resolvê-los têm um ganho enorme de legitimidade quando ingressam nas matrizes curriculares dos sistemas educacionais em seus diversos níveis, a começar pelos superiores, ao mesmo tempo em que preparam as geraçóes principiantes para a nova prática paradigmática em seu cotidiano profissional, colaborando para a consolidaçáo de sua hegemonia. Ainda que Kuhn houvesse escrito sua obra pensando nas ditas ciências naturais, alertando inclusive para usos espúrios de suas teses, parece pacífica a apropriação dessa sua análise da importância da curricularizaçáo dos paradigmas para a sua afirmação junto às comunidades atinentes quando tratamos das ciências humanas.

No que diz respeito ao nosso tema, pode-se afirmar sem medo de errar que o uso das geotecnologias em estudos históricos frequenta apenas de forma contingencial e esporádica os currículos das faculdades de História do Brasil. $\mathrm{Na}$ maior parte das vezes, quando isso acontece, é por conta da tenacidade de algumas iniciativas isoladas, dentre as quais aquelas relatadas em artigos que acompanham esse texto.

Em nossa experiência na Unifesp, tal defasagem entre os participantes do Hímaco - alunos e professores - e a maioria de seus colegas no curso de História muitas vezes dificultou a interlocução e o envolvimento nas atividades do grupo. Por exemplo, muitos editais para bolsas de iniciação científica ligadas aos nossos projetos tiveram poucas inscriçóes, dado o desconhecimento quase absoluto do tipo de trabalho envolvido. Além disso, as candidaturas ao mestrado em história da Unifesp quase nunca puderam ser associadas mais diretamente às humanidades digitais ou ao SIG histórico. Tal situação só começou a mudar quando as temáticas das humanidades digitais e do SIG histórico começaram, ainda 
que timidamente, a comparecer às salas de aula de nossa graduação, o que se deu a partir de 2015.15

No segundo semestre daquele ano, ministrei, em conjunto com minha colega Andréa Slemian, a disciplina denominada Laboratório de Ensino de Pesquisa, cujo objetivo é a de capacitar os alunos no trato das fontes históricas para a produção de conhecimento. Dentro desse escopo, e com o apoio, a boa vontade e a abertura da Professora Slemian, foi introduzida no curso a discussão dos influxos das novas tecnologias no mundo atual e as consequentes reconfiguraçóes do ofício do historiador, dentro do contexto mais geral da afirmação das chamadas humanidades digitais. Além disso, os alunos executaram um treinamento no tutorial de SIG do Hímaco, com a orientação de monitores do grupo. Ao final do curso, os alunos entregaram mapas produzidos por eles que tiveram como suporte a documentação e a história da cidade de São Paulo, fazendo uso do software gvSIG.

Já no primeiro semestre de 2017, dei um curso com o título "História, Mapas e Computadores", dessa vez compartido com meu colega Fernando Atique. O curso valeu como disciplina eletiva de graduação do curso de História da Unifesp e também como curso de extensão a interessados, dentre eles funcionários do Arquivo do Estado.16 Como consta da ementa da disciplina, seu objetivo era "(...) abordar o impacto das humanidades digitais no ofício do historiador, fazendo-o a partir da capacitação no uso das geotecnologias em investigaçóes históricas e da correlata reflexâo acerca das implicaçôes metodológicas e epistemológicas envolvidas. A história da cidade de São Paulo de fins do século XIX e inícios do XX servirá de objeto privilegiado para a concretização empírica da temática do curso". Nesse escopo, o projeto

\footnotetext{
${ }^{15}$ Os editais de bolsas passaram a ser bem mais concorridos e a seleção de mestrado ocorrida em 2017 aprovou, pela primeira vez, duas candidaturas relacionadas ao SIG histórico e associadas aos projetos do Hímaco.

${ }^{16} \mathrm{O}$ curso foi realizado nas dependências do Apesp e atendeu a exigência do Termo de Convênio entre a Unifesp e esta instituição.
} 
Pauliceia 2.0 serviu de objeto privilegiado de discussão e de aplicação prática dos conceitos teóricos abordados. Como desdobramento do aprendizado, no dia 25 de outubro de 2017 foram realizadas as Primeiras Jornadas de SIG Histórico da Unifesp, onde os trabalhos desenvolvidos no curso puderam ser apresentados a um público mais amplo. Uma das sessóes do evento, denominada Pauliceia 1.5 e apresentada por membros do Hímaco, pretendeu ser um exercício prévio ao uso da plataforma do projeto, ao incorporar em uma mesma visualização os diversos planos de informaçóes que os alunos produziram. Os trabalhos apresentados foram comentados pelos Professores Hugo Segawa, da FAU/USP, e Rosely Delboux, da Universidade Mackenzie. Como resultado, vários dos alunos se mostraram interessados em participar do desenvolvimento do projeto e da utilização da plataforma.

Em suma, a importância de se ensinar SIG histórico em nossas salas de aula não se refere apenas à difusão de uma tecnologia que em muito pode colaborar para o avanço de nossa área, mas também à necessidade desse aprendizado vir acompanhado de reflexôes dedicadas ao impacto do mundo digital em nosso ofício de historiador. As humanidades, a disciplina histórica dentre elas, já se transformaram radicalmente com o influxo das tecnologias digitais, e a ausência dessa discussão no mundo acadêmico não anula esse impacto, apenas o torna mais problemático e ameaçador, por desconhecido.

\subsection{A reCEPtividade E as ResistênCIas ao SIG histórico NO MEIO ACADÊMICO}

Apesar dos resultados promissores dessas iniciativas, não é demasiado insistir no caráter eventual delas. A disciplina de Laboratório é obrigatória e fixa na matriz do curso, mas ministrada em um sistema de rodízio entre todos os professores do Departamento, e a eletiva que teve lugar em 2017 não está incorporada ao currículo, e uma nova edição sua depende de muitas variáveis. 
Por outro lado, a ausência, quase sempre, ou a presença intermitente, quando muito, do SIG histórico em sala de aula não significa que os ambientes acadêmicos respectivos sejam necessariamente refratários às iniciativas inovadoras. No caso da Unifesp, é bem o contrário que tem acontecido. Nas duas oportunidades em que se propôs a inclusão desse tema em disciplinas do curso, como discutido acima, os colegas do Departamento não interpuseram nenhuma objeção ou dificuldade. A oferta de um curso fora das dependências da Universidade, inclusive, como foi o caso da eletiva ministrada no Arquivo do Estado, contou com total apoio do Departamento, apesar das dificuldades logísticas e burocráticas envolvidas.

Além disso, quando da discussão da recente reconfiguração do campus, as humanidades digitais tiveram seu espaço reconhecido. No primeiro semestre de 2016 foram inauguradas as novas instalaçóes da Unifesp de Guarulhos, e um ano depois terminadas as reformas das antigas. Em uma das salas do novo edifício acadêmico se encontra o Laboratório de Humanidades Digitais, espaço compartilhado por cinco grupos de pesquisas do campus, o Hímaco dentre eles. Ali existem doze estaçóes de trabalho, sendo seis em uso pelo Hímaco, com equipamentos adquiridos por financiamentos de projetos do grupo.

Para além do ambiente da Unifesp, a parceria com o Arquivo Público do Estado também expressa a valorização do SIG histórico como forma de produzir conhecimento. O Apesp, que tem sua participação no projeto disciplinada por um termo de convênio com a Unifesp para esse fim, disponibilizou para o uso do Hímaco um laboratório com quatro estaçóes de trabalho e uma mesa de reuniôes, nas dependências do Núcleo de Acervo Cartográfico. O espaço, além de abrigar várias das atividades da equipe e muitas de suas reunióes, também serviu para facilitar o contato com pesquisadores interessados em colaborar com o projeto Pauliceia 2.0. Além disso, o Apesp sediou e ajudou a divulgar e organizar o evento de apresentação

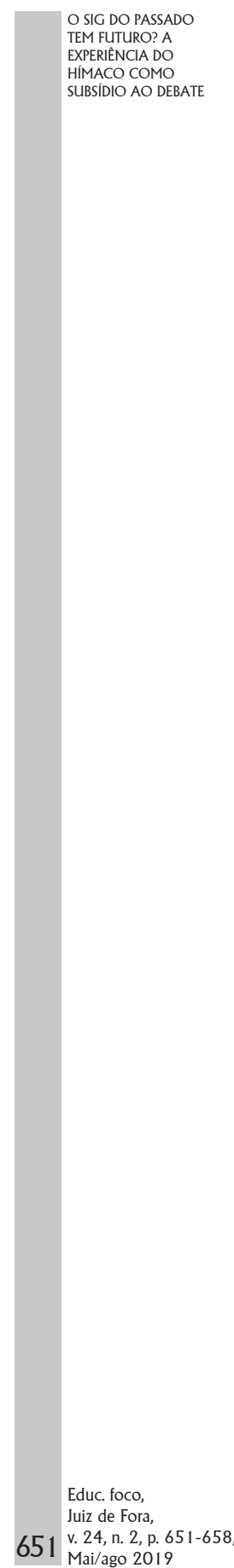


do projeto e o curso "História, Mapas e Computadores", já referidos mais acima.

No âmbito das agências fomentadoras de pesquisa, o financiamento do Programa eScience da Fapesp parece indicar uma valorização mais decidida das humanidades digitais também nesse esfera, ao fim e ao cabo decisiva para a viabilização de pesquisas nessa direção. Não se pode negar que as áreas disciplinares tradicionais que organizam a avaliação dos pedidos de financiamento muitas vezes têm dificuldades em tratar com as humanidades digitais, dadas as suas características inovadoras e a interdisciplinariedade de suas propostas.

Assim, no que diz respeito à experiência do grupo Hímaco, em seu contexto específico, o balanço referente à aceitação do SIG histórico no ecossistema em que atua pode ser considerado claramente positivo, a despeito da sua náo curricularização mais definitiva no curso de graduação em História da Unifesp. Esta é uma questão mais complexa, que não depende apenas do reconhecimento da importância da tecnologia para o ensino de história e o consequente aprimoramento da capacitação de nossos alunos. Dentre outras coisas, depende da existência de um grupo de docentes dedicados mais estritamente ao tema, o que se ressente justamente da ausência do tema na educação formal da geração que hoje dá aula nas universidades, estruturando um ciclo vicioso que só pode ser rompido de maneira mais mediada no tempo. Deve-se considerar, ainda, que a atuação em humanidades digitais e em SIG histórico ainda não encontra a resposta adequada dos sistemas de avaliação do trabalho docente. Os parâmetros e critérios que ali prevalecem ainda não incorporaram devidamente as novas modalidades de difusão do conhecimento que as novas tecnologias propiciam. Como exemplo, o mapa produzido pelo Hímaco da enchente de 1929 em São Paulo (Figura 1), de presumível importância historiográfica, e que consumiu dois anos de trabalho do grupo, tem pequena valoração em processos avaliativos das 
diversas instâncias acadêmicas e governamentais, se tanto. Assim também se dá com uma infinidade de produtos de projetos de humanidades digitais, como web-portais, plataformas on-line, infraestruturas de dados digitais, etc.

\subsection{Repercussấo das ATIVIdades do Hímaco}

Dando prosseguimento à análise pendular de desafios e oportunidades envolvidos no uso de SIG em história, no que se refere a estas últimas, um indicativo modesto de que é chegada a hora de uma maior difusão das geotecnologias entre os historiadores pode ser dado pela repercussão das iniciativas do grupo Hímaco no meio acadêmico. Vale destacar algumas veiculaçóes importantes, dado o alcance delas. Por duas vezes, os projetos do grupo foram objeto da Revista Pesquisa Fapesp, tratados em matérias de capa da ediçáo n. 214, de dezembro de 2013 (Fioravanti, 2013), e n. 255, de maio de 2017 (Ferla e Marques, 2017). A primeira trouxe informaçóes sobre o projeto do mapeamento das enchentes, e a segunda, do projeto Pauliceia 2.0, dentro de uma matéria sobre humanidades digitais. Esse também foi objeto de entrevista na Rádio USP (Ferla, Marques, Caravieri e Alves, 2017), de matéria da Imprensa Oficial de Sáo Paulo, em maio de 2017 (Ferla e Marco, 2017; disponível em www.imprensaoficial. com.br/DO/BuscaDO 2001 Documento_11_4. aspx?link=/2017/executivo $\% 2520$ secao $\% 2520 \mathrm{ii} /$ abril/06/ pagnot_0003_CEAQL0IU9DJVLe60E9PAOPEDHHN. pdf\&pagina $=$ III \&data $=06 / 04 / 2017 \&$ caderno $=$ Executivo $\% 20$ II\&paginaordenacao $=3$, acessado em 21 de junho de 2019), de uma edição do programa Brasil com Ciência, da TVT, em março de 2019 (https://www.youtube.com/ watch?v=QoVnkGZEcLY\&t=2422s, acessado em 10 de junho de 2019), e de matéria da revista Entreteses, da Unifesp, em junho de 2019 (Guerra, Ferla e Almeida, 2019; http://www. unifesp.br/reitoria/dci/images/DCI/revistas/Entreteses/

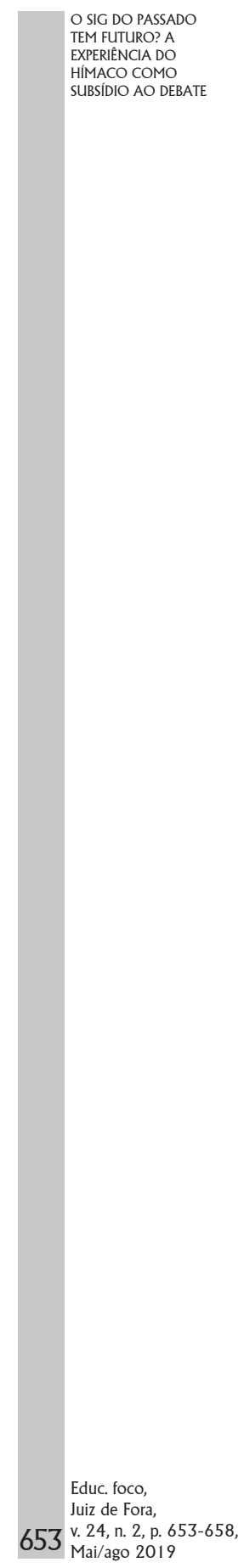




\begin{abstract}
LuIs FRLRA EntreTeses11_junho2019.pdf, acessado em 20 de junho de 2019). 17

Em setembro de 2014, o Hímaco foi incluído no Projeto "Around DH in 80 Days", uma iniciativa dedicada a divulgar projetos de humanidades digitais ao redor do mundo. O Hímaco é visitado no dia 59 da jornada.18 Ainda no âmbito internacional, em fevereiro de 2017 a Office of Global Strategy and Initiatives da Emory University publicou em seu site entrevista sobre as conexôes que levaram à participação daquela Universidade no Projeto Pauliceia 2.0.19

Muito dessa repercussão 20 atende à estratégia do próprio grupo em divulgar amplamente o seu trabalho, principalmente ao que se relaciona com o projeto Pauliceia 2.0, pois o seu caráter aberto e colaborativo tem na ampla participação da comunidade de historiadores a principal condição para o seu sucesso.
\end{abstract}

\title{
5. CONCLUSÃO
}

O trabalho acadêmico, atualmente, é cada vez mais estruturado em rede, possibilidade, aliás, estimulada e condicionada pelas novas tecnologias. Quando se trata de algo inovador e relativamente incipiente, como é o uso de SIG em estudos históricos no Brasil, torna-se ainda mais estratégica a articulação entre os poucos profissionais envolvidos. Disso resultaram alguns eventos de alcance nacional e internacional,

\footnotetext{
${ }^{17}$ Trata-se de edição especial da revista acerca dos 25 anos da Unifesp, trazendo alguns projetos de pesquisa destacados nesse percurso. O projeto Pauliceia 2.0 foi um dos três escolhidos dos 10 anos de existência do campus Guarulhos da Universidade.

${ }^{18}$ Ver em www.arounddh.org/jekyll/update/2014/08/19/day59; site acessado em 25 de março de 2018.

${ }^{19}$ Disponível em http://global.emory.edu/news-events/news/2017/february/ fapesp-winners.html, acessado em 25 de março de 2018.

${ }^{20}$ Para mais informaçóes sobre as repercussóes das atividades do Hímaco, consultar no site do grupo (www.unifesp.br/himaco) a aba "histórico", dentro da aba "quem somos".
} 
onde historiadores que fazem uso de SIG em suas pesquisas tiveram a oportunidade de apresentar e discutir suas metodologias e seus resultados. 21

Essas interlocuçóes permitem a troca de experiências e a discussão de estratégicas para otimizar as oportunidades e minimizar as dificuldades que compóem o binômio que acompanha toda reflexão que trata do uso de SIG em história. Esse é o grande mérito do projeto desse dossiê, e essa também foi a intenção da escritura do presente texto. A experiência do grupo Hímaco foi apresentada aqui como subsídio para o debate, que já está em curso e que deve ser aprofundado. Longe de pretender ser um percurso paradigmático, o relatado acima quer servir como material de crítica e debate, a compor com outras narrativas o enredo das aventuras dos historiadores no mundo temível e fascinante dos computadores.

\section{BIBLIOGRAFIA}

Albagli, Sarita; Maciel, Maria Lucia; Abdo, Alexandre (orgs). 2015. questôes abertas. Brasília: IBICT; Rio de Janeiro: Unirio.

Bodenhamer, David. 2008. "History and GIS: implications for the discipline”. In: Knowles, 2008.

Ferla, Luis et al. 2016. Mapeamento SIG na Pesquisa e Inventário do Patrimônio Arqueológico de Guarulhos (PIPAG). , São Paulo, n. 26, p. 84- 94.

\footnotetext{
${ }^{21}$ Com destaque para os três Seminários "Sistemas de Informaçôes Geográficas em História” realizados até o momento, o primeiro na UFMG, em 2012; o segundo na UFF, em 2015; e o terceiro no Arquivo Público de São Paulo, em 2016; e para e para as reunióes virtuais mensais organizadas pelos Profs. Carlos Valencia e Tiago Gil no âmbito de Rhitmo - Red de Investigación Hispanoamérica em los Tiempos Modernos (http://rhitmo.institutomora.edu.mx/subred_sistemas_ informacion, acessado em 25 de março de 2018).
}

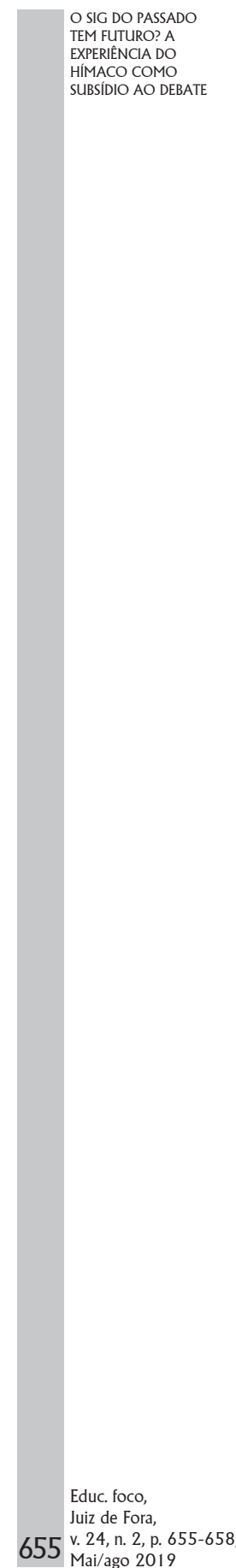


Ferla, Luis; Marco, Simone de. 2017. Arquivo Público e Unifesp apresentam Pauliceia 2.0 - história de São Paulo. , 127(65), III, São Paulo: Imprensa oficial.

Ferla, Luis; Marques, Fabrício; Caravieri, Sarah; Alves, Dagoberto. 2017. Projeto pauliceia 2.0. . Rádio USP (disponível em: http://revistapesquisa.fapesp.br/2017/05/26/ podcast-luis-ferla/; acessado em 18 de janeiro de 2018).

Ferla, Luis; Marques, Fabrício. 2017. Como São Paulo se urbanizou - plataforma vai reunir dados georreferenciados sobre a transformação da capital paulista entre 1870 e 1940. , ed. 255 (disponível em: http://revistapesquisa.fapesp. br/2017/05/23/arealidade-que-emerge-da-avalanche-dedados/; acessado em 18 de janeiro de 2018).

Fioravanti, Carlos. 2013. Entre paredes de concreto: Mapas históricos exibem as transformações na forma e na função de rios encobertos por avenidas. , ed. 214 (disponível em: http:// revistapesquisa.fapesp.br/2013/12/18/entre-paredes-deconcreto/; acessado em 18 de janeiro de 2018).

Gregory, Ian; Ell, Paul. 2007. Technologies, methodologies and scholarship. Cambridge: Cambridge University Press.

Guerra, José Luis; Ferla, Luis; Almeida, Cintia Rodrigues. Compartilhando histórias de São Paulo, , n. 11, junho de 2019 (disponível em: www.unifesp.br/reitoria/dci/images/DCI/ revistas/Entreteses/EntreTeses11_junho2019.pdf, acessado em 20 de junho de 2019).

Jorge, Janes. 2006. São Paulo: Alameda.

Knowles, Anne (ed.). 2008. how maps, spatial data, and GIS are changing historical scholarship. Redlands: Esri Press.

Kogan, Gabriel. 2013. Unesco IHE, Msc Thesis. 
Latour, Bruno. 2000. como seguir cientistas e engenheiros sociedade afora. São Paulo: Ed. Unesp.

Pontes, José Alfredo. 1995. In: Sáo Paulo: Departamento de Patrimônio Histórico da Eletropaulo/ Eletropaulo, no 5.

Santos, Fábio. 2011. salubridade e ocupaçáo do espaço na cidade de São Paulo, 1875- 1930. São Paulo: Alameda/ Fapesp.

Seabra, Odette. 1984. Valorização dos rios e das várzeas na cidade de São Paulo. Tese de doutoramento. Universidade de São Paulo. 
